\title{
METHODS FOR EVALUATING THE EFFICIENCY OF YOUTH POLICY ACTIVITIES
}

\author{
Novikov S.V.*, Sorokin A.E., Candidates of Economic Sciences \\ Moscow Aviation Institute (National Research University), Moscow, Russia \\ *E-mail: ncsrm@mail.ru
}

\begin{abstract}
Within the framework of main areas of youth policy implementation the conditions necessary for the successful socialization of young people are created. In this regard, the macro-level indicator for youth activities is the area of the youth policy where it is implemented. Linking to the specific areas of youth policy implementation allows for the creation of a system of activities that would enable operation of the areas that are most relevant to the field in which youth policy activities are implemented, as well as consideration the criteria and indicators developed to date in order to assess the efficiency of youth policy. Thus, the proposed material is based on the activities held by student associations involved in the competitive selection of the development programs of the Ministry of Education and Science of the Russian Federation. The article outlines the methods for evaluating the efficiency of youth policy activities and proposes measures to improve the performance of institutions of higher education that are falling behind in this area.
\end{abstract}

\section{KEY WORDS}

Student associations, youth policy, institutions of higher education, student association development programs, information coverage, performance evaluation procedure.

Methods for evaluating the efficiency of youth policy activities have not been wellestablished today and do not have common universally-accepted standards, rules and traditions yet. A systematic approach to the evaluation of youth policy activities involves the reliance on a system of criteria for the efficiency of youth policy as a whole. The difficulty is that the system of criteria and indicators for the efficiency of youth policy has not been developed yet. The matter of youth policy efficiency remains a problem and a debating issue.

In general, youth policy efficiency can be considered in relation to its targets and its specific areas. However, this approach appears to be somewhat simplistic, excluding the resulting and resource elements of the general concept of youth policy efficiency. The structure of the general concept of the youth policy efficiency can be defined as the relation between the objective, the result and the means by which the goal of specific youth policies is achieved. Effectiveness is an important criterion for evaluating any social project, including youth policy. In the case of youth policy, effectiveness implies the changes in relation to young people to which the given system of measures will lead (mainly of a program-target nature) in the process of implementation of this policy.

It should be noted that the effectiveness of youth policy at the design stage is most closely related to the feasibility of the project itself (in this case, of the program areas being developed). Feasibility is defined through a preliminary analysis of the conformity to the intended internal and external conditions in which the programs will be implemented. The effectiveness of youth policy can be defined as a system of specific measurable, qualitative and/or quantitative indicators that are the product of a target-oriented and consistent implementation of a given system of activities for the development of a model for assessing the youth policy efficiency.

On the base of youth policy effectiveness its efficiency is defined. Youth policy efficiency in its turn is a comprehensive indicator of the interaction effectiveness among youth policy actors [in the sociological sense] in the implementation process of this policy, showing the relation between specific outcomes and resource costs (social and economic efficiency), which establishes the correspondence between results and the problem field at which main effort has been directed at the conceptual and implementation stages of the 
youth policy activities. Accordingly, it is possible to speak of youth policy efficiency as such when the latter is determined by the ability of its areas to conform to the real problems of young people and to speak of the implementation efficiency of the youth policy that manifests itself in the availability of the necessary resources (organizational, human, communication, financial, etc.) of the entity, the legal mechanisms for its implementation, and the activity and effort of young people themselves.

Youth policy can be considered efficient if the positive, desirable effect exceeds negative effect and side results. Moreover, the principle of efficiency must relate to a system of values and ethical standards. Efficient youth policy is also impossible without full awareness of young people of the measures taken to implement it. In this regard, it would be appropriate to address the conditions that ensure the efficiency of youth policy. The latter may be classified as: the adequacy of the chosen model of youth policy to social realia (quality characteristics of the main mechanisms for implementing youth policy meeting the real conditions at different levels); providing with a solid social basis for youth policy; sustainability of the social basis; socially-oriented interests of youth policy subjects; correspondence of the organization structures of youth policy to the tasks to be performed; the interaction of youth policy structures with all the parties concerned; the effectiveness of the interaction between different branches and levels of youth policy among themselves; the professionalism of the management personnel of youth policy; taking into account the specific nature of the implementation of youth policy at different levels (federal, regional, local); ideological and theoretical-methodological support for youth policy; the system for evaluating the youth policy efficiency; social monitoring in the area of youth policy using an indicator system to monitor the dynamics of youth policy phenomena and processes.

Issues related to the system for evaluating the efficiency of youth policy should be given special attention, more precisely with its theoretical and practical embodiment within a given model.

An analysis of sources including program projects, concepts and scientific articles on youth policy in the Russian Federation, revealed the following important circumstance: the actual absence of a functional model for evaluating the efficiency of youth policy and, in general, the declarative nature of measures to develop and implement particular actions to deal with the situation.

This complicates and hinders the development of constructive processes in the area of youth policy, thereby further exacerbating the situation.

The model for evaluating youth policy efficiency is presented as parameters expressed through specific indicators that provide information about the extent to which obtained results correspond to those initially laid within the framework of the social project.

The basis necessary for the development of the model for evaluating youth policy efficiency is a clearly defined system of criteria, which predefines a characteristic space for evaluation parameters classification.

In discussing the criteria for the youth policy efficiency, the following important circumstance, most often mentioned in various studies, should be noted. Often, in evaluating youth policy efficiency, consideration is given mainly to socio-economic criteria. In the current phase, insufficient attention has been paid to socio-political, ethnical and social, organizational and ideological criteria.

It is equally productive to propose a different set of criteria for the main areas of society life that have been proposed within the framework of the juventology concept in the context of the analysis of young people's socialization. Within the framework of this concept the economic, political, meso-social and ethnical-cultural spheres are the main areas of the society.

The problem of developing the criteria for evaluating the youth policy efficiency can be addressed in the overall context of setting targets and the appropriate youth policy areas to address and overcome negative trends in the youth environment caused by a set of problems. 
Thus, the following scheme can be proposed: the problematic field in a youth environment is establishing goals and objectives for youth policy, identifying its areas, developing a system of efficiency criteria for each of the areas.

The ranking of the evaluation criteria developed is possible through the identification of priority areas for youth policy.

There is also a problem in the operationalization of the selected criteria, the identification of their specific parameters, for which a system of indicators is subsequently developed, which is essential for measuring the effectiveness of youth policy. In our view, the indicators should: relate to a certain level of implementation of the youth policy (federal, regional, local); reflect links both vertically - between the indicators of different levels and horizontally - between the indicators of the same level.

The indicators for evaluating the youth policy efficiency are to be considered as the qualitative and quantitative characteristics developed in the system of social relationships of the youth with political and social actors.

The system of indicators should meet the following requirements:

1. The set and form of indicators should be limited and permanent for a specified period of time.

2. Indicators should, to the extent possible, reflect youth policy phenomena, which are well-studied scientifically and tested in practice; at the same time, in transition from one socio-economic form to another, it is possible to use indicators of a searchable, innovative nature.

3. Periodic adjustments to the set of indicators used should be made.

In the light of the above mentioned points, one of the most important tasks that researchers (both practitioners and theoreticians) in the area of youth policy face today is to develop an effective system of indicators within a given model for youth policy efficiency.

Thus, the model for evaluating youth policy efficiency includes the following key aspects for its development: a system of criteria and their respective evaluation parameters; the development of qualitative and quantitative indicators for each of the parameters.

The discussion of issues in the context of addressing the problematic aspects of the youth policy efficiency, its evaluation at different levels of development and the implementation of the latter cannot be exhaustive without an analysis of the internal arrangement of youth policy. In this case, we are talking about the "mechanism" aspects of its development and implementation. Their analysis will identify the possible reasons for the actual absence of functional models for the youth policy and the evaluation of its efficiency, develop the specific mechanisms whose malfunction has led to such a situation.

The task of the state youth policy is to integrate the separate programs and projects that are designed for young people into a single whole. They should be integrated by the basic goals and priorities of state youth policies, which must be implemented at all levels of implementation.

The selection of priority areas of state youth policy as the basic ones for educational organizations should be based on the main objective of youth policy: the formation of socially active citizens. The students should not be regarded primarily as the object of education and socialization. They should be the direct participants in the solution of national problems.

Accordingly, the strategic priority of the state youth policy is to create the conditions for the formation of the personality which would be harmonious, permanently improving, knowledgeable, competitive, caring, with a strong moral and ethical core, capable of adapting to changing circumstances and receptive to new creative ideas. Therefore, in the challenging task of developing a multi-layered system for evaluating the efficiency of youth policy activities, where activity efficiency indicators should correlate with the indicators of higher levels (e.g. subprograms or programs in which it is implemented), the mega-level indicator is a specific condition for the formation of such a personality, which is ultimately facilitated by this or that particular activity.

Conclusion. The use of too many indicators in assessing the efficiency of the activities appears to be hardly effective because of the difficulty of obtaining information, especially in 
the case of different types of activities. Three sets of indicators should be used to assess the efficiency of youth policy activities: statistical data, direct and indirect indicators system, sociological measurements results. Statistic data on students are necessary for the calculation of target indicators, the direct indicators describe the quantitative parameters of the activities implemented, whereas qualitative parameters can only be evaluated by means of indirect indicators. Thus, on the basis of sociological measurements data, the effectiveness of the activities and the quality of their implementation can be judged upon.

\section{REFERENCES}

1. Volkov Y.G. Role of creative social practices in the development of united activities in russian society. International Journal of Environmental and Science Education. 2016. №16. pp. 9398-9409.

Novikov S.V. Innovative methods for work process design in a high technology enterprise. Russian Journal of Agricultural and Socio-Economic Sciences. 2017. T. 68. №8. pp. 114-117.

2. Kulikov S.P., Shchitov K.V. Political subjectivity phenomenon of student-age youth. Russian Journal of Agricultural and Socio-Economic Sciences. 2017. №10. pp. 81-83.

3. Zolotukhina E.B. Sales management of the chain retail establishments. International Journal of Applied Business and Economic Research. 2017. №11. pp. 19-27.

4. Mindlin Y.B., Novikov S.V., Kireev S.V., Adamenko A.A., Belitskaya O.V. Innovative territorial clusters. International Journal of Economics and Financial Issues. 2016. №8. pp. 251-256.

5. Kulikov S.P. Educational work as a mechanism for increasing the electoral activity of student youth. Bulletin of the RMAT. 2015. №1. pp. 103-108.

6. Yurkina L.V., Kulikov S.P. Harmonious educational space of a technological university is the key to the formation of citizenship. European Social Science Journal. 2013. №3(31). pp. 55-60.

7. Kulikov S.P. Student self-government in the new Russia: the history of development and the current state in the context of the political socialization of youth. Historical, philosophical, political and legal sciences, culture and art history. Questions of theory and practice. 2011. №8-1. pp. 117-120.

8. Kulikov S.P. Patriotic education of youth as the main direction of youth policy. Bulletin of the Moscow State Regional University. Series: Pedagogy. 2015. №2. pp. 140-145.

9. Novikov S.V., Meshankov D.V. Realization of modern personnel policy in Russia: challenges and threats. Competitiveness in the global world: economy, science, technology. 2017. №3-3(34). pp. 113-115.

10. Tikhonov A.I, Novikov S.V. Institutional aspects of the state personnel policy in Russia. Management and business administration. 2017. №2. pp. 25-32.

11. Nikolaev A.V. Evaluation of the effectiveness of professional activities of public civil servants. Russian technological journal. 2014. No. 4 (5). pp. 284-295.

12. Tikhonov A.I. Opposition to deception in personnel work. Teaching-methodical manual / Stavropol, 2017.

13. Korzhueva L.M., Novikov S.V. Development of regulatory support and prerequisites for the formation of an innovative educational complex. In the collection: Post-crisis outlines of innovative processes Materials of the Tenth Drucker readings. Ed. R.M. Nizhegorodtsev. 2010. pp. 237-241.

14. Korzhueva L.M. Perfection of the system for assessing the effectiveness of innovative target programs of the educational complex. Proceedings of the MAI. 2010. №41. p. 25.

15. Gusakov A.G., Novikov S.V. Problems of balancing the system of staff motivation at Russian enterprises. In the collection: Issues and problems of economics and management in the modern world, a collection of scientific papers on the results of an international scientific and practical conference. 2016. pp. 264-266.

16. Chaika N.K. Method for assessing the level of development of the corporate governance system. Bulletin of the Moscow Aviation Institute. 2016. 23. 23. №4. pp. 218-224. 